Тихонов Александр Андреевич, студент, кафедра «Подъемно-транспортные и дорожные машины, Белгородский государственный технологический университет им. В.Г. Шухова, г. Белгород, Россия

РАСЧЕТ КОЭФФИЦИЕНТА ДИНАМИЧНОСТИ ВИБРАЦИОННОГО УСТРОЙСТВА С АССИМЕТРИЧНЫМИ КОЛЕБАНИЯМИ

\title{
CALCULATION OF THE COEFFICIENT OF DYNAMIC VIBRATORY DEVICE WITH ASYMMETRIC OSCILLATIONS
}

В статье предоставлен расчёт коэффициентов динамичности вибрационного устройства с ассиметричными колебаниями по четырем ступеням.

Ключевые слова: вибропогружатель лабораторно-исследовательский, компьютерная программа ВИБРО, набор дебалансов.

Создание вибрационных машин с направленной асимметричной вынуждающей силой - одно из современных направлений совершенствования вибрационного технологического оборудования. Данная лабораторная работа выполняется с использованием вибрационного стенда, позволяющего генерировать асимметричные колебания [1].

Асимметричные колебания позволяют получать существенную разницу по величине между составляющими вынуждающей силы, действующими в противоположных направлениях. Из двух направлений действия вынуждающей силы, как правило, можно выделить «рабочее» направление действия и «холостое». В «рабочем» направлении выполняется полезная работа: уплотнение грунта, забивание или выдёргивание свай, подбрасывание сортируемого материала на просеивающей плоскости. В «холостом» направлении наряду с тем, что происходит накапливание энергии и кинематическая перегруппировка элементов механизма, может выполняться вредная работа, такая как подбрасывание конструкции машины, принудительное сжатие пакета пружин и др., для чего необходимо применять дополнительные меры, например использование пригрузов [3]. 
«Наука и образование: новое время» № 2, 2018

Величина составляющей вынуждающей силы в рабочем направлении может обозначаться как $P_{\mathrm{p}}$, а в направлении холостого хода $-P_{\mathrm{x}}$. Отношение этих величин может называться динамическим коэффициентом $k_{\text {д или }}$ коэффициентом асимметрии вынуждающей силы. Коэффициент динамичности может быть больше единицы, если $k_{\text {д }}=P_{\mathrm{p}} / P_{\mathrm{x}}$, или меньше единицы, если используется обратная величина $-P_{\mathrm{x}} / P_{\mathrm{p}}$. В настоящее время создание асимметричных колебаний стараются достичь сложением направленных колебаний, создаваемых несколькими механизмами с направленными колебаниями, установленными последовательно друг за другом в виде нескольких ступеней [2].

В области разработки и создания механизмов с асимметричными колебаниями ведутся интенсивные исследования. В цель таких исследований включается ряд задач, которые можно сформулировать следующим образом:

• получение наибольшего значения динамического коэффициента

$$
k_{\text {д }}=P_{\mathrm{p}} / P_{\mathrm{X}}
$$

• получение наибольшего значения динамического коэффициента наименьшим числом ступеней [5];

- определение оптимального значения динамического коэффициента и числа ступеней для конкретной технологической операции.

Обычно, в корпусе вибрационного механизма установлены несколько пар валов с дебалансами или несколько параллельно установленных вибраторов с круговыми колебаниями. Каждая горизонтальная пара валов (дебалансов) образует вибратор направленных колебаний с частотой вращения $n_{1}, n_{2}, \ldots, n_{\mathrm{i}}$. Каждой частоте вращения вала соответствует дебаланс массой: $m_{1}, m_{2}, \ldots, m_{\mathrm{i}}$, соответственно [4].

Для расчёта проектных параметров вибрации в практическом занятии используется разработанная программа с использованием пакета Excel. Программа рассчитана на работу семи ступеней направленных колебаний.

Каждая пара дебалансных валов генерирует синусоидальные колебания: 
«Наука и образование: новое время» № 2, 2018

$$
y_{i}=A_{i} \cdot \cos \left(\omega_{i} t+\varphi_{i}\right)
$$

где $i$ - порядковый номер вибратора с направленными колебаниями, $i=1,2, \ldots, n$ [4]; $\varphi$ - начальная фаза, рад.

При одновременной работе вибраторов с различной частотой вращения валов, например, 500, 1000, 1500, 2000, 2500, 3000 об/мин, происходит сложение колебаний, в результате чего, происходит изменение величины вынуждающей силы и характер изменения величины вынуждающей силы во времени. Характер изменения вынуждающей силы во времени достаточно полно оценивается в пределах одного периода колебаний по наименьшей частоте вращения дебалансного вала, при $n=500$ об/мин.

При сложении колебаний нескольких вибраторов, результирующая вынуждающая сила может быть описана уравнением:

$$
P_{n}=\sum_{i=1}^{n} A_{i} \cdot \cos \left(\omega_{i} t+\varphi_{i}\right),
$$

где $P_{n}$ - суммарная величина вынуждающей силы, Н.

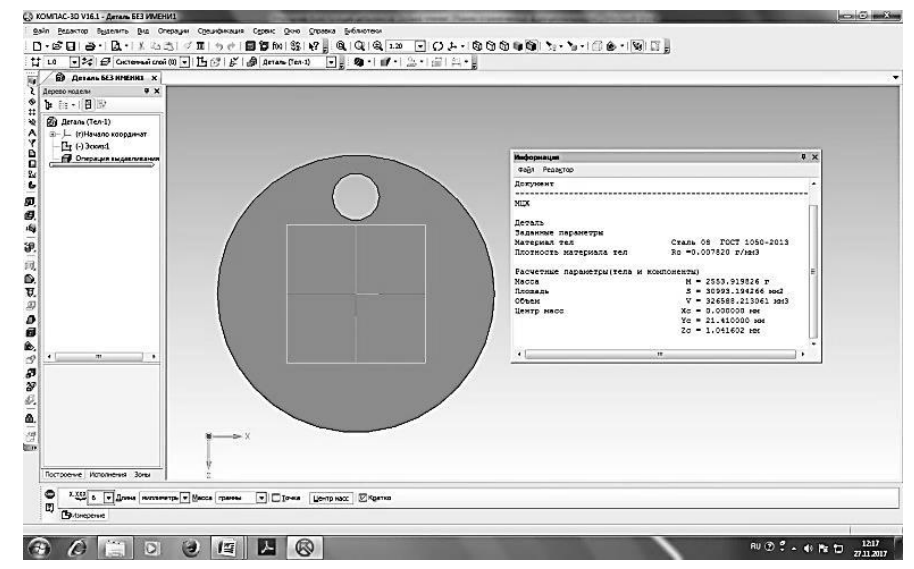

Рисунок 1 - Построение и расчет дебаланса №1

Величину коэффициента динамичности определяем с помощью программы разработанной на кафедре ПТ и ДМ [6].

Таблица 1 - Коэффициенты динамичности

\begin{tabular}{|l|c|c|c|c|}
\hline \multicolumn{1}{|c|}{ № вибратора } & $\mathbf{1}$ & $\mathbf{2}$ & $\mathbf{3}$ & $\mathbf{4}$ \\
\hline Масса, кг & 2.55 & 0.882 & 0.305 & 0.297 \\
\hline Радиус, см & 3.6 & 1.57 & 1.363 & 0.098 \\
\hline Нач. фаза, град & 0 & 0 & 0 & 0 \\
\hline Скорость, об/мин & 500 & 1000 & 1500 & 2000 \\
\hline
\end{tabular}


«Наука и образование: новое время» № 2, 2018

\begin{tabular}{|l|c|c|c|c|}
\hline $\mathrm{R}, \mathrm{M}$ & 0.036 & 0.0157 & 0.01363 & 0.00098 \\
\hline Fi0, рад & 0.00 & 0.00 & 0.00 & 0.00 \\
\hline $\mathrm{W}, 1 / \mathrm{c}$ & 52.36 & 104.72 & 157.08 & 209.44 \\
\hline
\end{tabular}

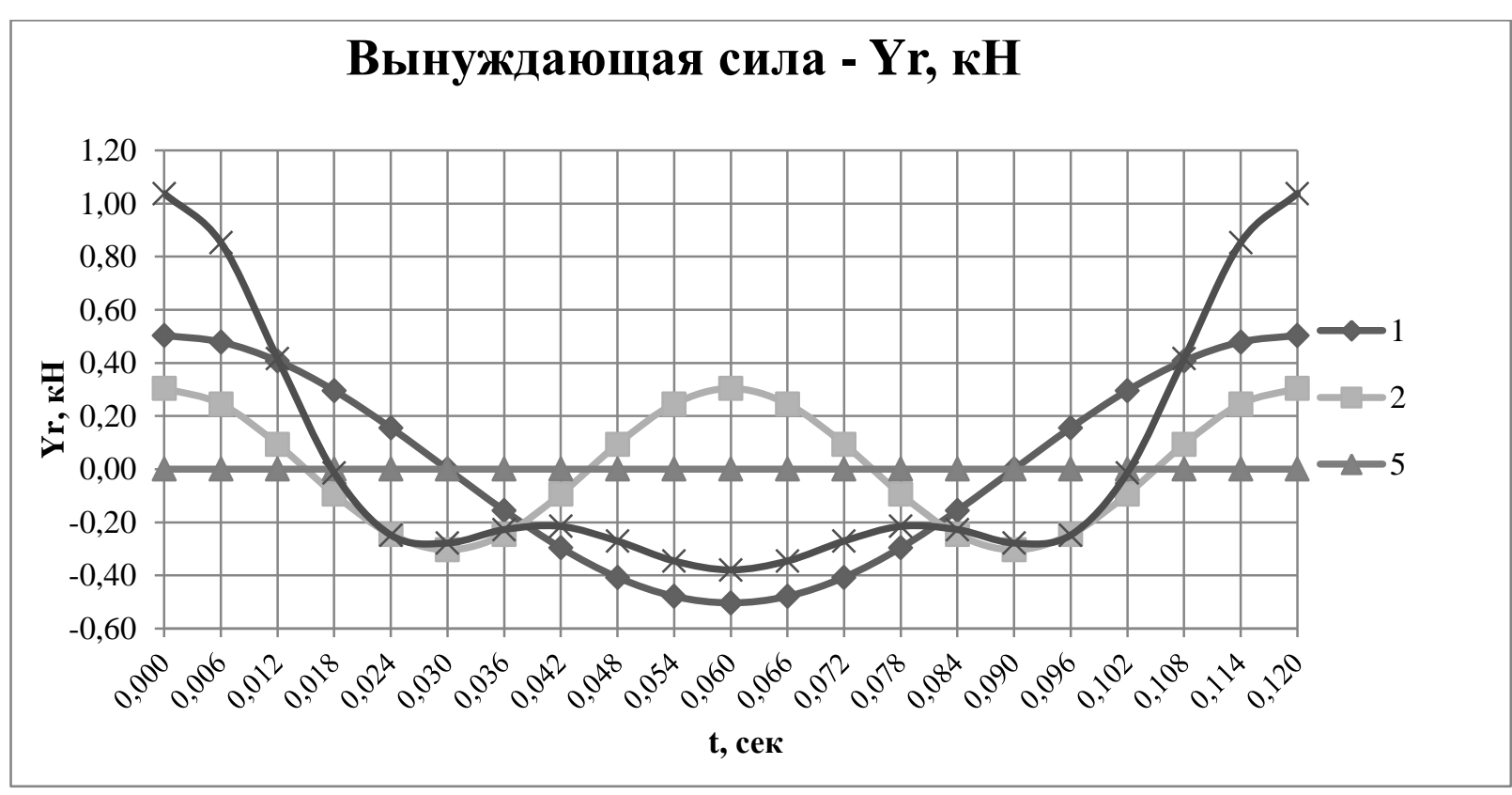

Рисунок 2 - Диаграмма вынуждающей силы

\section{СПИСОК ЛИТЕРАТУРЫ}

1. Клюев С.В., Клюев А.В. Предель идентификациии природных и инженерных систем // Фундаментальные исследования. - 2007. - №12-2. - С. 366-367.

2. Клюев С.В., Клюев А.В. Управление проектными параметрами в задачах оптимального проектирования // Строительная механика инженерных конструкций и сооружений. - 2010. - №1. - C. 15-19.

3. Клюев С.В., Клюев А.В. Оптимальное проектирование конструкиий с учетом устойчивости равновесия // Фундаментальные исследования. - 2008. - № 9. - С. 62.

4. Клюев С.В. Основы конструктивной организации природных и искусственных материалов / Современные технологии в промышленности строительных материалов $u$ стройиндустрии: сб. студ. докл. Международного конгресса: В 2 ч. Ч. 1. - Белгород: Изд-во БГТУ им. В.Г. Шухова, 2003. - С. 161.

5. Уральский В.И., Шаталов А.В., Синица Е.В., Уральский А.В. Теория механизмов и машин: учеб. пособие для студентов, обучающихся по направлению 230302. - Белгород: Изд-во БГТУ им. В.Г. Шухова, 2016. - С. 124-128.

6. Гончаров С.И., Синица Е.В. Детали машин и основы конструирования: лабораторный практикум для студентов, обучающихся по направлению 151900.62. - Белгород: Изд-во БГТУ им. В.Г. Шухова, 2011. - С. 78. 